\title{
PERENCANAAN REHABILITASI SALURAN INDUK DAERAH IRIGASI CIBINUANGEUN DI KABUPATEN LEBAK PROVINSI BANTEN
}

\author{
Restu Candra, Rino Dwi Sadi, Ma'ulfi Kharis Abadi \\ Program Studi Teknik Sipil, Universitas Banten Jaya, Jl. Raya Ciwaru II No.73 Kota Serang, Banten \\ Email: restuchandra23@gmail.com \\ Email: rsadisons@gmail.com \\ Email:maulfikharisabadi@unbaja.ac.id
}

\begin{abstract}
ABSTRAK
Irigasi adalah usaha penyediaan dan pengaturan air untuk lahan pertanian. Tujuan utama dari penelitian ini adalah untuk perencanaan rehabilitasi pada saluran induk daerah irigasi cibinuangeun Kabupaten Lebak yang berada di Provinsi Banten. Saluran induk berfungsi untuk membawa air dari jaringan utama ke saluran sekunder dan petak tersier. Bahannya dapat terbuat dari pasangan batu, beton atau pasangan batu dan beton. Saluran induk Cibinuangeun mengandalkan sumber air dari sungai Cibinuangeun melalui bangunan bendung Cibinuangeun. Daerah Irigasi Cibinuangeun memiliki luas fungsional 2570 ha. Kondisi saluran induk Cibinuangeun tersebut saat ini terdapat banyak kerusakan, yang mengakibatkan pengaliran air tidak optimal sehingga perlu dilakukan perencanaan rehabilitasi dengan cara memeriksa langsung kondisi saluran di lokasi untuk mengetahui volume kerusakan dan menghitung biaya rehabilitasi pada saluran tersebut. Metode Penelitian yang digunakan adalah Kriteria Perencanaan Irigasi yang diterbitkan oleh Kementerian Pekerjaan Umum Direktorat Jenderal Sumber Daya Air sebagai dasar standar perencanaan irigasi. Hasil Penelitian diketahui saluran induk berbentuk trapesium dan debit aliran yang tersedia sekarang tidak sesuai dengan perencanaan awal dibangunnya saluran induk cibinuangeun, karena adanya sedimentasi dan kerusakan pada dinding dan lantai saluran yang bocor. Tingkat kerusakan saluran induk mencapai $47,37 \%$ dari total panjang saluran induk 950 meter. Rencana biaya yang dibutuhkan untuk rehabilitasi saluran induk cibinuangeun adalah empat ratus tujuh puluh juta empat ratus ribu rupiah.
\end{abstract}

Kata Kunci : saluran primer/induk, debit, dimensi saluran irigasi, rehabilitasi saluran

\begin{abstract}
Irrigation is an effort to provide and regulate water for agricultural land. The main objective of this study is to plan the rehabilitation of the main channel of Cibinuangeun irrigation area, Lebak Regency, Banten Province. The main channel serves to carry water from the main network to the secondary channel and tertiary plot. The material can be made of masonry, concrete or masonry and concrete. The Cibinuangeun main channel relies on a water source from the Cibinuangeun river through the Cibinuangeun weir building. The Cibinuangeun Irrigation Area has a functional area 2570 ha. The condition of the Cibinuangeun main canal currently has a lot of damage, which results in water drainage being not optimal so it is necessary to plan for rehabilitation by directly examining the condition of the canals at the location to determine the volume of damage and calculate the cost of rehabilitation on the channel. The research method used is the Irrigation Planning Criteria issued by the Ministry of Public Works, Directorate General of Water Resources as the basis for standard irrigation planning. The results showed that the trapezoidal trunk channel and the current available flow rate were not in accordance with the initial planning of the Cibinuangeun main channel construction, due to sedimentation and damage to the walls and floor of the leaking channel. The level of damage to the main line reached 47,37\% of a total trunk length of 950 meters. The planned cost required for the rehabilitation of the Cibinuangeun main channel is four hundred seventy million four hundred thousand rupiah.
\end{abstract}


Keywords: primary/main line, discharge, irrigation canal dimensions, channel rehabilitation

\section{PENDAHULUAN}

Air merupakan komponen penting untuk keberlangsungan hidup manusia dan makhluk hidup lainnya. Maka perlu adanya system pengelolaan air yang baik untuk menunjang kebutuhan tersebut dan mendukung program pemerintah seperti swasembada pangan, menjadikan kebutuhan air untuk pertanian sangatlah penting, diperlukan fasilitas penunjang berupa saluran irigasi agar pembagian air merata untuk setiap petak sawah. Daerah Irigasi Cibinuangeun merupakan daerah irigasi Kewenangan Provinsi Banten yang terdapat di Kabupaten Lebak. Lokasi bendungnya terdapat di Desa Bolang, Kecamatan Malingping. Sumber air untuk memenuhi kebutuhan air pada daerah irigasi Cibinuangeun adalah Sungai Cibinuangeun dengan luas catchment area seluas 2.570 hektar. Pendistribusian air dari Sungai Cibinuangeun diambil menggunakan bangunan utama (Head Works) berupa bendung tetap yang bersifat permanen kemudian di alirkan ke saluran induk. Namun pada saat ini kondisi saluran induk tersebut terdapat banyak kerusakan. Dari persoalan di atas dan ditinjau sangat pentingnya fungsi saluran irigasi maka diperlukannya perbaikan pada saluran induk tersebut.

\section{METODOLOGI PENELITIAN}

Metode yang digunakan oleh penulis dalam penelitian ini adalah metode penelitian deskriptif yaitu penelitian yang bertujuan untuk membuat deskripsi secara sistematis, faktual, serta akurat pada fakta dan sifat populasi atau daerah tertentu. Dalam pengumpulan data metode yang digunakan yaitu dengan cara studi lapangan (field research) yaitu untuk memperoleh data primer dan data sekunder.

\section{DATA DAN ANALISA}

\section{A. Hasil Inventarisasi Saluran Induk Melalui Observasi}

Pengukuran saluran induk dilakukan dari titik awal saluran sampai titik akhir saluran dengan jarak 50 meter dari total panjang saluran 950 meter. Sketsa penampang melintang saluran akan diukur terlihat pada gambar 1 dan hasil pengukuran penampang pada tabel 1.

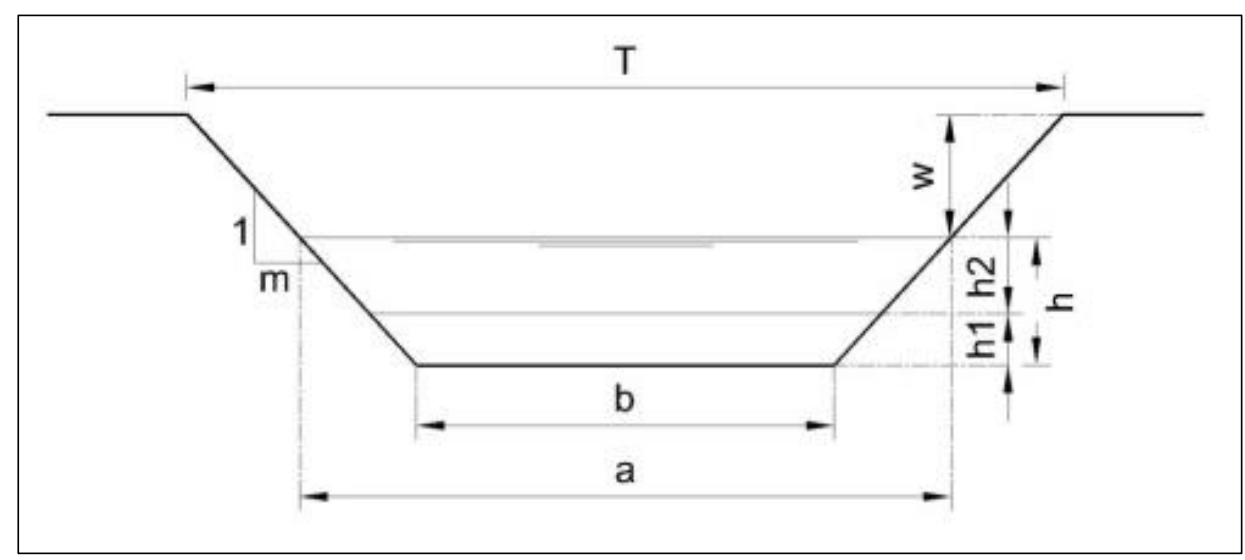

Gambar 1 Penampang melintang saluran trapesium 
Journal JOSCE Vol.03 No.01 Februari 2021

Tabel 1 Hasil pengukuran penampang hidrolis saluran

\begin{tabular}{|c|c|c|c|c|c|c|c|c|c|}
\hline No & $\begin{array}{c}\text { Ruas } \\
\text { Saluran }\end{array}$ & $\begin{array}{l}\text { HM } \\
\text { meter }\end{array}$ & $\begin{array}{c}\mathrm{T} \\
\text { meter }\end{array}$ & $\begin{array}{c}\mathrm{a} \\
\text { meter }\end{array}$ & $\begin{array}{c}\mathrm{b} \\
\text { meter }\end{array}$ & $\begin{array}{c}\mathrm{m} \\
\text { meter }\end{array}$ & $\begin{array}{c}\mathrm{h} \\
\text { meter }\end{array}$ & $\begin{array}{c}\mathrm{h} 2 \\
\text { meter }\end{array}$ & $\begin{array}{c}\mathrm{w} \\
\text { meter }\end{array}$ \\
\hline 1 & Ruas 1 & HM.0+000 & 6.30 & 4.10 & 3.00 & 1,00 & 0.60 & 0 & 1.20 \\
\hline 2 & Ruas 1 & HM.0+050 & 6.30 & 4.10 & 3.00 & 1,00 & 0.60 & 0 & 1.20 \\
\hline 3 & Ruas 1 & HM.0+100 & 6.30 & 4.10 & 3.00 & 1,00 & 0.60 & 0.45 & 1.20 \\
\hline 4 & Ruas 1 & HM.0+150 & 6.30 & 4.10 & 3.00 & 1,00 & 0.60 & 0.45 & 1.20 \\
\hline 5 & Ruas 1 & HM.0+200 & 6.30 & 4.10 & 3.00 & 1,00 & 0.60 & 0.45 & 1.20 \\
\hline 6 & Ruas 1 & HM.0+250 & 6.30 & 4.10 & 3.00 & 1,00 & 0.60 & 0.45 & 1.20 \\
\hline 7 & Ruas 1 & HM.0+300 & 6.30 & 4.10 & 3.00 & 1,00 & 0.60 & 0.45 & 1.20 \\
\hline 8 & Ruas 1 & HM.0+350 & 6.30 & 4.10 & 3.00 & 1,00 & 0.60 & 0.45 & 1.20 \\
\hline 9 & Ruas 1 & HM.0+400 & 6.30 & 4.10 & 3.00 & 1,00 & 0.60 & 0.40 & 1.20 \\
\hline 10 & Ruas 1 & HM.0+450 & 6.30 & 4.10 & 3.00 & 1,00 & 0.60 & 0.40 & 1.20 \\
\hline 11 & Ruas 1 & HM.0+500 & 6.30 & 4.10 & 3.00 & 1,00 & 0.60 & 0.40 & 1.20 \\
\hline 12 & Ruas 1 & HM.0+550 & 6.30 & 4.10 & 3.00 & 1,00 & 0.60 & 0 & 1.20 \\
\hline 13 & Ruas 1 & HM.0+600 & 6.30 & 4.10 & 3.00 & 1,00 & 0.60 & 0 & 1.20 \\
\hline 14 & Ruas 1 & HM.0+650 & 6.30 & 4.10 & 3.00 & 1,00 & 0.60 & 0 & 1.20 \\
\hline 15 & Ruas 2 & HM.0+700 & 6.00 & 3.81 & 2.80 & 1.00 & 0.55 & 0 & 1.15 \\
\hline 16 & Ruas 2 & HM.0+750 & 6.00 & 3.81 & 2.80 & 1.00 & 0.55 & 0 & 1.15 \\
\hline 17 & Ruas 2 & HM.0+800 & 6.00 & 3.81 & 2.80 & 1.00 & 0.55 & 0.40 & 1.15 \\
\hline 18 & Ruas 2 & HM.0+850 & 6.00 & 3.81 & 2.80 & 1.00 & 0.55 & 0.40 & 1.15 \\
\hline 19 & Ruas 2 & HM.0+900 & 6.00 & 3.81 & 2.80 & 1.00 & 0.55 & 0.40 & 1.15 \\
\hline 20 & Ruas 2 & HM.0+950 & 6.00 & 3.81 & 2.80 & 1.00 & 0.55 & 0 & 1.15 \\
\hline
\end{tabular}

Sumber : Hasil Observasi dilapangan, 2020

Menghitung analisa hidrolika bertujuan untuk mendapatkan debit aliran yang masuk ke saluran induk dengan menggunakan rumus debit menurut Strikler.

1. Ruas 1 saluran induk pada HM. 0+000 s/d HM. 0+650

Data observasi :

$$
\begin{aligned}
\mathrm{b} & =3 \mathrm{~m} \\
\mathrm{~h} & =0,60 \mathrm{~m} \\
\mathrm{~m} & =1
\end{aligned}
$$

Luas penampang $\mathrm{A}=(\mathrm{b}+\mathrm{mh}) \mathrm{h}$

$\mathrm{A}=(3+(1 \times 0,60)) \times 0,60$

$$
=2,160 \mathrm{~m}^{2}
$$

Keliling basah $\mathrm{P}=\mathrm{b}+2 \mathrm{~h} \sqrt{1+\mathrm{m}^{2}}$

$\mathrm{P}=3+(1,2 \times 1,414)$

$$
=4,6968 \mathrm{~m}
$$

Radius hidrolis $\mathrm{R}=\frac{\mathrm{A}}{\mathrm{P}}$

$$
\begin{aligned}
\mathrm{R} & =\frac{2,160}{4,6968} \\
& =0,460 \mathrm{~m}
\end{aligned}
$$

Kecepatan aliran $\mathrm{V}=\mathrm{k} \mathrm{R}^{2 / 3} \cdot \mathrm{I}^{1 / 2}$

$$
\begin{aligned}
\mathrm{V} & =60 \times 0,460^{2 / 3} \times 0,0005^{1 / 2} \\
& =60 \times 0,595897 \times 0,0223 \\
& =0,797 \mathrm{~m} / \mathrm{det}
\end{aligned}
$$

Debit aliran $\mathrm{Q}=\mathrm{V} \times \mathrm{A}$

$\mathrm{Q}=0,797 \times 2,160$

$$
=1,722 \mathrm{~m}^{3} / \mathrm{det}
$$

2. Ruas 2 saluran induk pada HM. $0+700$ s/d HM. 0+950

Data observasi : 


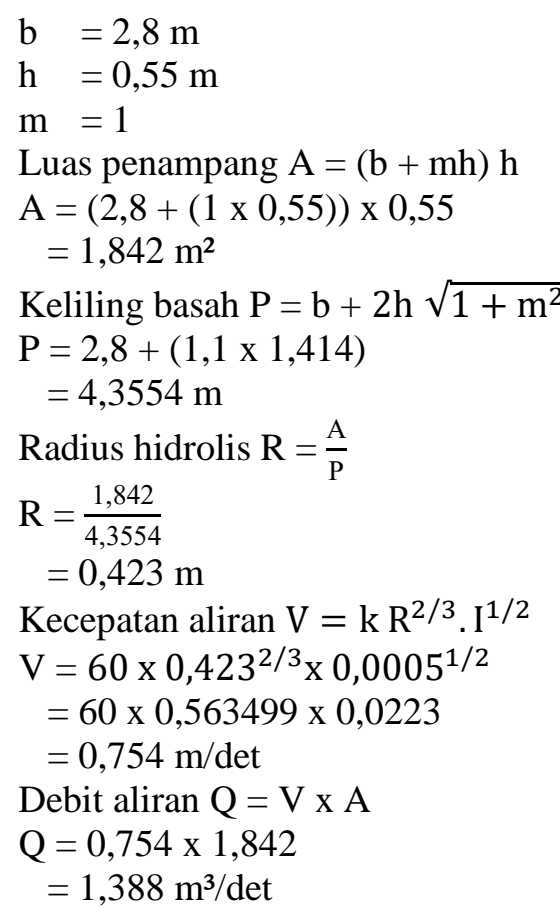

Rekapitulasi kriteria kerusakan dapat dilihat pada tabel 2.

Tabel 2 Rekapitulasi kriteria kerusakan saluran induk untuk rehabilitasi

\begin{tabular}{ccccc}
\hline No & Titik Kerusakan & $\begin{array}{c}\text { Kriteria } \\
\text { Rehabilitasi }\end{array}$ & $\begin{array}{c}\text { Panjang } \\
\text { kerusakan } \\
(\mathrm{m})\end{array}$ & Keterangan \\
\hline 1 & HM 0+200 s/d HM 0+260 & Sedang & 60 & Perbaikan pada lining dan \\
& lantai \\
2 & HM 0+850 s/d HM 0+856 & Sedang & 6 & Perbaikan pada lining dan \\
4 & HM 0+100 s/d HM 0+350 & Sedang & 250 & Penggalian sedimen \\
5 & HM 0+400 s/d HM 0+500 & Sedang & 100 & Penggalian sedimen \\
5 & HM 0+800 s/d HM 0+900 & Sedang & 100 & Penggalian sedimen \\
\hline
\end{tabular}

Sumber : Hasil Rekap dan pengolahan Data, 2020

\section{B. Menghitung Volume Kerusakan}

Setelah mengetahui langkah-langkah pekerjaan dan cara perhitungan luas dan volume pekerjaan selanjutnya dilakukan perhitungan luas dan volume pekerjaan. Setelah dilakukan perhitungan volume pekerjaan pada HM 0+200 sampai dengan HM 0+250 dan HM 0+850 sampai dengan HM 0+856 diketahui total volume pasangan batu sebanyak $171.42 \mathrm{~m} 3$, pekerjaan siaran sebanyak $320.52 \mathrm{~m} 2$, pekerjaan plesteran sebanyak $52.8 \mathrm{~m} 2$ dan pekerjaan bongkaran batu sebanyak $171.42 \mathrm{~m} 3$.

\section{Rencana Anggaran Biaya}

Standar Harga Satuan (SSH) mengacu pada SSH Kabupaten Lebak tahun 2020 dan Analisa Harga Satuan Pekerjaan (AHSP) mengacu pada AHSP Kementerian Pekerjaan Umum Bidang Cipta Karya tahun 2013. Setelah diketahui analisa harga satuan dan di dapatkan harga setiap item pekerjaan yang telah direkapitulasi pada tabel 3 berikut. 
Tabel 3 Rekapitulasi analisa harga satuan

\begin{tabular}{clcc}
\hline No. & \multicolumn{1}{c}{ Uraian } & Satuan & Harga Satuan (Rp.) \\
\hline 1 & \multicolumn{1}{c}{2} & 3 & \\
\hline 1. & Pengukuran kembali (Uitzet) & $\mathrm{m}^{\prime}$ & $4,700.00$ \\
2. & Papan Nama Pekerjaan & $\mathrm{bh}$ & $1,428,200.00$ \\
3. & Direksi Keet/ Gudang / Los kerja - Sewa & $\mathrm{Ls}$ & $4,800,000.00$ \\
4. & Galian Lumpur sedalam s.d 1 m secara manual & $\mathrm{m} 3$ & $190,500.00$ \\
5. & Pasangan Batu campuran 1 pc : 4 pp & $\mathrm{m} 3$ & $1,686,700.00$ \\
6. & Siaran campuran 1 pc : 3 pp & $\mathrm{m} 2$ & $104,500.00$ \\
7. & Plesteran tebal 1 cm campuran 1 pc : 3 pp & $\mathrm{m} 2$ & $115,000.00$ \\
8. & Bongkar Pasangan batu (manual) & $\mathrm{m} 3$ & $217,800.00$ \\
\hline
\end{tabular}

Sumber : AHSP Kementerian Pekerjaan Umum Bidang Cipta Karya, 2013

Berdasarkan hasil rencana anggaran biaya bahwa total biaya yang dibutuhkan untuk perencanaan rehabilitasi saluran induk cibinuangeun di tambah dengan PPN 10\% adalah sebesar Rp 470.400.000,00 (empat ratus tujuh puluh juta empat ratus ribu rupiah)

\section{Jadwal Pelaksanaan Pekerjaan}

Jadwal pelaksanaan pekerjaan direncanakan dalam empat bulan pengerjaan agar pekerjaan dapat selesai dengan optimal dari segi kualitas dan kuantitas dan diketahui kemajuan pekerjaan dimulai pada minggu ke-1 sebesar 0\% sampai dengan minggu ke-16 sebesar 100\%.

\section{KESIMPULAN DAN SARAN}

\section{A. Kesimpulan}

1. Kondisi komponen hidraulika pada saluran induk cibinuangeun sebagai berikut

a. Debit aliran yang tersedia sekarang tidak sesuai dengan perencanaan awal dibangunnya saluran induk cibinuangeun, hal ini disebabkan menumpuknya sedimentasi pada saluran induk sehingga menghambat aliran air dan menyebabkan kapasitas air berkurang. Dapat dilihat masih banyaknya areal sawah yang tidak terairi secara maksimal.

b. Dimensi saluran induk juga mengalami kerusakan seperti adanya longsor dibeberapa titik dan adanya saluran yang bocor sehingga mengakibatkan debit air berkurang dan memperkecil dimensi saluran.

c. Banyaknya kerusakan fisik yang terjadi pada saluran induk diantaranya terlihat pada lining dan lantai saluran, kerusakan ini disebabkan oleh pengaruh alam dan usia saluran yang sudah melewati masa layanan.

2. Tingkat kerusakan fisik pada saluran induk sepanjang 450 meter diantaranya kerusakan dinding dan lantai saluran, terdapat juga sedimentasi. Jika dipersentasekan kerusakan dinding dan lantai sepanjang 66 meter sekitar 6,95\%, untuk sedimentasi terdapat di sepanjang 450 meter dan jika di persentasekan sekitar 47,37\% dari total panjang keseluruhan saluran induk adalah 950 meter.

3. Berkurangnya kapasitas saluran akibat pengaruh sedimentasi berdampak pada terhambatnya kecepatan aliran air dan berkurangnya debit air pada saluran induk cibinuangeun.

4. Rencana anggaran biaya untuk perencanaan rehabilitasi saluran induk cibinuangeun adalah sebesar Rp. 470,400,000.00 (Empat Ratus Tujuh Puluh Juta Empat Ratus Ribu Rupiah).

\section{B. Saran}

1. Untuk mendapatkan hasil perhitungan yang tepat dan lebih akurat dalam pengukuran saluran induk disarankan melakukan pengukuran menggunakan alat ukur seperti theodolite, total station dan pengukuran dilakukan dengan jarak per - 25 meter. 
2. Bangunan irigasi mempunyai umur masa layanan, sebaiknya jika sudah mencapai masa layanan tersebut untuk segera melakukan tindakan perbaikan agar fungsi bangunan irigasi tetap bisa berfungsi dengan baik.

3. Diharapkan para petani meningkatkan partisipasi dalam kegiatan pengamanan jaringan irigasi seperti saling membantu dalam pengaturan air, menjaga fasilitasi saluran agar bangunan pada daerah irigasi cibinuangeun tetap bisa berfungsi dengan optimal.

\section{DAFTAR PUSTAKA}

Hansen, V, R, dan G. E. Stringhan, (1992), Dasar-dasar Praktek Irigasi,Terjemahan Erlangga, Jakarta Indarto, (2016). Metode Analisis dan Tool untuk Interpretasi Hidrograf Aliran Sungai, Jakarta Kementerian Pekerjaan Umum Direktorat Jenderal Sumber Daya Air, (2013), Kriteria Perencanaan Irigasi KP-01, Jakarta.

Kementerian Pekerjaan Umum Direktorat Jenderal Sumber Daya Air, (2013), Kriteria Perencanaan Irigasi KP-02, Jakarta.

Kementerian Pekerjaan Umum Direktorat Jenderal Sumber Daya Air, (2013), Kriteria Perencanaan Irigasi KP-03, Jakarta.

Kementerian Pekerjaan Umum dan Perumahan Rakyat Badan Pengembangan Sumber Daya Manusia, (2017), Modul 08 Rehabilitasi Jaringan Irigasi, Bandung.

Peraturan Mentri Pekerjaan Umum No. 32, (2017), Penyelenggaraan Operasi Jaringan Irigasi, Jakarta Peraturan Pemerintahan Republik Indonesia No. 23, (1982), Tentang Irigasi, Jakarta

PT. Multi Guna Karya, (2016), Updating Pengelolaan Aset Irigasi Daerah Irigasi Cibinuangeun, Serang Soedarsono, (2006), Irigasi dan Bangunan Air, STT Banten Jaya, Serang,

Victor Miguel Ponce, (1989), Engineering Hydrology, Principles and Practices, San Diego State University, New Jersey. 